\title{
A novel c.197T $\rightarrow$ A variant among Brazilian neonates with glucose-6-phosphate dehydrogenase deficiency
}

\author{
José Pereira de Moura Neto ${ }^{1,2}$, Marcos Vinícius Dourado ${ }^{1}$, Mitermayer Galvão dos Reis ${ }^{1}$ \\ and Marilda Souza Gonçalves ${ }^{1,2}$ \\ ${ }^{1}$ Centro de Pesquisas Gonçalo Moniz, Fundação Oswaldo Cruz, Salvador, BA, Brazil. \\ ${ }^{2}$ Faculdade de Farmácia, Universidade Federal da Bahia, Salvador, BA, Brazil.
}

\begin{abstract}
Glucose-6-phosphate dehydrogenase (G6PD, EC 1.1.1.49) deficiency is the most common enzyme deficiency worldwide, causing a spectrum of diseases including neonatal hyperbilirubinemia and acute or chronic hemolysis. We used the methemoglobin reduction test and G6PD electrophoresis to screen 655 neonates ( 354 females and 301 males) for common G6PD mutations in the city of Salvador in the Northeastern Brazilian state Bahia and found that 66 (10.1\%) were G6PD-deficient (41 females and 25 males). The 66 (10.1\%) G6PD-deficient neonates were assessed for the c.376 $A \rightarrow G$ (exon 5) and c.202 G $\rightarrow A$ (exon 4) mutations using the polymerase chain reaction and restriction enzyme fragment length polymorphism (PCR-RFLP) analysis and the results validated by DNA sequencing. Of the 66 G6PD-deficient neonates investigated we found that $54(81.8 \%)$ presented the $c .376 \mathrm{~A} \rightarrow \mathrm{G}$ (p.Asn126Asp) and c.202 G $\rightarrow$ A (p.Val68Met) mutations, two (3\%) had the c.376 A $\rightarrow$ G mutation only, two (3\%) had the c.202 G $\rightarrow$ A mutation only, five (7.6\%) exhibited a previously unrecorded 197T $\rightarrow$ A (p.Phe66Thr) substitution in exon 4 and three showed no mutations at any of these sites. Of the five neonates exhibiting the new 197T $\rightarrow A$ (p.Phe66Thr) substitution, four (6.1\%) also presented the c.202 $\mathrm{G} \rightarrow \mathrm{A}$ and c.376 A $\rightarrow \mathrm{G}$ mutations and one (1.5\%) had the c.[197T $\rightarrow$ A / $202 \mathrm{G} \rightarrow \mathrm{A}$ ] combination. We propose to name the new variant G6PD Bahia.
\end{abstract}

Key words: glucose-6-phosphate dehydrogenase deficiency, G6PD mutations, neonatal screening.

Received: March 29, 2007; Accepted: September 18, 2007.

The incidence of glucose-6-phosphate dehydrogenase (G6PD, EC 1.1.1.49) deficiency fluctuates greatly among different racial groups, affecting approximately 400 million people worldwide (Beutler and Vulliamy, 2002). According to a World Health Organization (WHO) report $7.5 \%$ of the world's population carry one or two mutations for G6PD deficiency, and 2.9\% are G6PD-deficient (WHO Working Group, 1989). Although over 400 genetically determined variants of G6PD have been reported only 176 of them are recognized, of which 122 are associated with different levels of G6PD deficiency (Beutler and Vulliamy, 2002). Early testing of G6PD activity may provide an etiological diagnosis for neonatal jaundice. The WHO recommends neonatal screening on cord blood samples in populations where G6PD deficiency is common because such screening can help in monitoring affected children, prevent acute hemolysis and inform parents not to give children with G6PD deficiency broad beans (Vicia faba, hence the

Send correspondence to Marilda Souza Gonçalves. Centro de Pesquisas Gonçalo Moniz, Fundação Oswaldo Cruz, Rua Waldemar Falcão 121, 40296-710 Salvador, BA, Brazil. E-mail: mari@ cpqgm.fiocruz.br. alternative common name of fava beans), which contain vicine, isouramil and convicine and can cause potentially fatal hemolytic anemia or "favism" (WHO Working Group, 1989).

Due to several waves of immigration, which resulted in cultural, socioeconomic and ethnic diversity, Brazil is a large country with a highly heterogeneous population. Salvador is the largest city in the Northeastern Brazilian state of Bahia, with a population of 2.7 million people (RIPSA2006) of which $86 \%$ is of African origin (Azevêdo et al., 1981). A previous study on the prevalence of G6PD deficiency in this population (Azevêdo et al., 1978) found a frequency of $11.39 \%$ among patients from the University Hospital Professor Edgard Santos in Salvador and 12.20\% among males from the same city, who were found to carry the A-, Mediterranean (Gd Med) and Minas Gerais (Gd $\mathrm{MG})$ variants.

There is a high A-prevalence in populations with African admixture (Azevêdo et al., 1980; Azevêdo et al., 1981). Individuals with this African variant carry the c. 376 $A \rightarrow G$ (p.Asn126Asp) mutation in association with the c.202 G $\rightarrow$ A (p.Val68Met), c.680 G $\rightarrow$ T (p.Arg227Leu) 
or the c.967 T $\rightarrow \mathrm{C}$ (p.Leu323Pro) mutations (Beutler and Vulliamy, 2002).

No previous surveys have investigated the types of $G 6 P D$ mutations in the Bahia population, which was the object of the present study, involving a group of neonates with G6PD deficiency from two public maternity hospitals in Salvador, Bahia. Cord blood samples were collected from 655 non-consanguineous neonates (354 (54\%) females and $301(46 \%)$ males) born between February and December 2000 in the Tsylla Balbino and Santo Amaro Hospitals, Salvador, Bahia, Brazil. The neonates showed no clinical or hematological changes and were not under oxidant situations. The study was approved by the Human Subject Research Ethics Committee of the Oswaldo Cruz Research Foundation and informed consent was obtained from the parents or guardians in accordance with the ethical principles and with the Helsinki Declaration of 1975, as revised in 2000.

The methemoglobin reduction test and G6PD electrophoresis were carried out in blood samples from all neonates (Brewer et al., 1960; Frank, 2005) and specific mutations were investigated in the neonates found to be G6PD-deficient. The c.202 G $\rightarrow$ A exon 4 and c.376 A $\rightarrow$ G exon 5 mutations were determined by extracting total DNA from each blood sample (QIAmp DNA Blood Kit, Valencia, $\mathrm{CA}$ ) and applying the polymerase chain reaction (PCR) amplification followed by restriction enzyme fragment length polymorphism (RFLP) analysis (Hirono et al., 2002). The mutations were validated by DNA sequencing (ABI 3100, Applied Biosystems, Foster City, CA). The PCR reaction used a total volume of $50 \mu \mathrm{L}$ containing $40 \mathrm{mM}$ Tris- $\mathrm{HCl}$ (pH 8.4), $50 \mathrm{ng}$ of DNA, $3 \mathrm{mM}$ of $\mathrm{MgCl}_{2}$, $10 \mathrm{pM}$ of each primer (GibcoBRL - Life Technologies, Brazil), $2 \mathrm{mM}$ of the dNTP mixture (Pharmacia Biotech, N.J., USA) and 0.25 units of Taq DNA polymerase. The reactions were carried out in a Mastercycler ${ }^{\circledR}$ gradient thermal cycler (Eppendorf) using an initial 10 min incubation at
$94{ }^{\circ} \mathrm{C}$, followed by 35 amplification cycles of denaturation at $94{ }^{\circ} \mathrm{C}$ for $1 \mathrm{~min}$, annealing at $56^{\circ} \mathrm{C}$ for $1 \mathrm{~min}$ and elongation at $72{ }^{\circ} \mathrm{C}$ for $1 \mathrm{~min}$, with a final elongation at $72{ }^{\circ} \mathrm{C}$ for $10 \mathrm{~min}$.

The methemoglobin reduction test was positive for 71 $(9.58 \%, 45$ females and 26 males) neonates, of which electrophoresis confirmed that $66(93 \%, 41$ females and 25 males) were G6PD-deficient and five females (7\%) were unconfirmed.

As regards mutations at the $G 6 P D$ gene (Table 1), 54 $(81.8 \%)$ neonates carried both the c.202 $\mathrm{G} \rightarrow \mathrm{A}$ and the c. $376 \mathrm{~A} \rightarrow \mathrm{G}$ mutations, two neonates (3\%) had only the c. $202 \mathrm{G} \rightarrow$ A mutation and two (3\%) only the c. $376 \mathrm{~A} \rightarrow \mathrm{G}$ mutation. Sequencing of exon 4 revealed that four female and one male $(7.6 \%)$ presented a c. $197 \mathrm{~T} \rightarrow$ A mutation, and that four $(6.1 \%)$ of these neonates with the $\mathrm{c} .197 \mathrm{~T} \rightarrow \mathrm{A}$ variant also had the c.202 $\mathrm{G} \rightarrow \mathrm{A}$ and c.376 A $\rightarrow$ G mutations while one neonate $(1.5 \%)$ had the $\mathrm{c} .202 \mathrm{G} \rightarrow$ A mutation. Two females and one male showed abnormal electrophoresis patterns (4.5\%), and the five females whose G6PD deficiency was unconfirmed by electrophoresis showed none of the mutations described above.

The presence of both the c.202 $\mathrm{G} \rightarrow \mathrm{A}$ and c.376 $\mathrm{A} \rightarrow \mathrm{G}$ mutations in most of the neonates confirms the high prevalence of the A- or African variant in Salvador. On the other hand, our finding of a c.202 $\mathrm{G} \rightarrow$ A mutation alone in two G6PD-deficient female neonates is a rare event that has been described just twice before (Hirono et al., 2002; Karadsheh et al., 2005).

The new mutation in nucleotide 197 (TTC $\rightarrow$ T $\underline{A C}$ ) predicts a phenylalanine to threonine substitution at amino acid residue 66, Phe66Thr (GenBank bankit 826430). It was found together with the c.202 $\mathrm{G} \rightarrow \mathrm{A}$ and c. $376 \mathrm{~A} \rightarrow \mathrm{G}$ mutations in three female neonates and one male neonate, and in combination with a sole c. $202 \mathrm{G} \rightarrow$ A mutation in one female, but was not found among 100 neonates without

Table 1 - Glucose-6-phosphate dehydrogenase (G6PD) mutations among 655 non-consanguineous neonates (354 (54\%) females and 301 (46\%) males) neonates born between February and December 2000 in the Tsylla Balbino and Santo Amaro Hospitals, Salvador, Bahia, Brazil.

\begin{tabular}{|c|c|c|c|c|c|}
\hline \multirow[b]{4}{*}{ Mutations } & \multicolumn{4}{|c|}{ Maternity hospital } & \multirow[b]{4}{*}{ Total (\%) } \\
\hline & \multicolumn{2}{|c|}{ Tsylla Balbino } & \multicolumn{2}{|c|}{ Santo Amaro } & \\
\hline & \multicolumn{4}{|c|}{ Number of G6PD-deficient neonates } & \\
\hline & Female & Male & Female & Male & \\
\hline c. $202 \mathrm{G} \rightarrow \mathrm{A}$ & 0 & 0 & 2 & 0 & $2(3.03)$ \\
\hline c. $376 \mathrm{~A} \rightarrow \mathrm{G}$ & 2 & 0 & 0 & 0 & $2(3.03)$ \\
\hline c. $[202 \mathrm{G} \rightarrow \mathrm{A} / 376 \mathrm{~A} \rightarrow \mathrm{G}]$ & 26 & 19 & 6 & 3 & $54(81.82)$ \\
\hline $197 \mathrm{~T} \rightarrow \mathrm{A} / 202 \mathrm{G}>\mathrm{A} / 376 \mathrm{~A} \rightarrow \mathrm{G}$ & 3 & 0 & 0 & 1 & $4(6.06)$ \\
\hline c. $[197 \mathrm{~T} \rightarrow \mathrm{A} / 202 \mathrm{G} \rightarrow \mathrm{A}]$ & 1 & 0 & 0 & 0 & $1(1.52)$ \\
\hline No mutations at these sites & 1 & 0 & 1 & 1 & $3(4.54)$ \\
\hline Total of G6PD-deficient neonates & 33 & 19 & 9 & 5 & $66(100)$ \\
\hline
\end{tabular}


G6PD deficiency in the same sample (data not shown). For this reason, this new variant might be related to G6PD deficiency. At the same codon, a 196T $\rightarrow$ A missense mutation (G6PD Songklanagarind), leading to Phe66Ile (TTC $\rightarrow$ ATC) substitution, has been described as a class II G6PD variant (Laosambat et al., 2005).

This was the first screening of the c. $202 \mathrm{G} \rightarrow \mathrm{A}$ and c.376 A $\rightarrow$ G G6PD gene mutations in Salvador, Bahia. We propose to name the $197 \mathrm{~T} \rightarrow$ A variant described here G6PD Bahia.

\section{Acknowledgments}

Financial support was provided by the Brazilian agency Fundação de Amparo à Pesquisa do Estado da Bahia (FAPESB) grant number 277/04).

\section{References}

Azevêdo ES, Alves AFP, Silva MCBO, Souza MGF, Lima AMVMD and Azevêdo WC (1980) Distribution of abnormal hemoglobins and glucose-6-phosphate dehydrogenase variants in 1200 school children of Bahia, Brazil. Am J Phys Anthropol 53:509-512.

Azevêdo ES, Silva KMC, Silva MCBO, Lima AMVMD, Fortuna CMM and Santos MG (1981) Genetic anthropological studies in the island of Itaparica, Bahia, Brazil. Hum Hered 31:353-357.

Azevêdo WC, Silva ML, Grassi MC and Azevêdo ES (1978) Glucose-6-phosphate dehydrogenase deficiency in a general hospital of Salvador, Bahia, Brazil. Rev Bras Pesq Med Biol $11: 49-52$.
Beutler E and Vulliamy TJ (2002) Hematologically important mutations: Glucose-6-phosphate dehydrogenase. Blood Cells Mol Dis 28:93-103.

Brewer GJ, Tarlov AR and Alving AS (1960) Methaemoglobin reduction test: A new, simple, in vitro test for identifying primaquine-sensitivity. Bull World Health Organ 22:633640.

Frank JE (2005) Diagnosis and management of G6PD deficiency. Am Fam Physician 72:1277-1282.

Hirono A and Beutler E (1988) Molecular cloning and nucleotide sequence of cDNA for human glucose-6-phosphate dehydrogenase variant A(-). Proc Natl Acad Sci 85:3951-3954.

Hirono A, Kawate K, Honda A, Fujii H and Miwa S (2002) A single mutation c. $202 \mathrm{G}>\mathrm{A}$ in the human glucose-6-phosphate dehydrogenase gene (G6PD) can cause acute hemolysis by itself. Blood 99:1498.

Karadsheh NS, Moses L, Ismail SI, Devaney JM and Hoffman E (2005) Molecular heterogeneity of glucose-6-phosphate dehydrogenase deficiency in Jordan. Haematologica 90:1693-1694.

Laosombat V, Sattayasevana B, Janejindamai W, Viprakasit V, Shirakawa T, Nishiyama K and Matsuo M (2005) Molecular heterogeneity of glucose-6-phosphate dehydrogenase (G6PD) variants in the south of Thailand and identification of a novel variant (G6PD Songklanagarind). Blood Cells Mol Dis 34:191-196.

World Health Organization (1989) Glucose-6-Phosphate Dehydrogenase Deficiency: Report of a WHO Working Group / Glucose-6-Phosphate Dehydrogenase Deficiency. WHO, Geneva, 77 pp.

\section{Internet Resource}

Rede Interagencial de Informações para Saúde(2006) Indicadores e dados básicos - Brasil 2006. http://tabnet.datasus.gov.br/ cgi/idb2006/matriz.htm.

Associate Editor: Francisco Mauro Salzano 